\title{
Polymerase activity of hybrid ribonucleoprotein complexes generated from reassortment between 2009 pandemic H1N1 and seasonal H3N2 influenza $A$ viruses
}

Wai Y Lam ${ }^{1}$, Karry LK Ngai ${ }^{1}$ and Paul KS Chan ${ }^{1,2^{*}}$

\begin{abstract}
Background: A novel influenza virus (2009 pdmH1N1) was identified in early 2009 and progressed to a pandemic in mid-2009. This study compared the polymerase activity of recombinant viral ribonucleoprotein (VRNP) complexes derived from 2009 pdmH1N1 and the co-circulating seasonal H3N2, and their possible reassortants.

Results: The $2009 \mathrm{pdmH1N1}$ VRNP showed a lower level of polymerase activity at $33^{\circ} \mathrm{C}$ compared to $37^{\circ} \mathrm{C}$, a property remenisence of avian viruses. The 2009 pdmH1N1 VRNP was found to be more cold-sensitive than the WSN or H3N2 vRNP. Substituion of 2009 pdmH1N1 vRNP with H3N2-derived-subunits, and vice versa, still retained a substantial level of polymerase activity, which is probably compartable with survival. When the 2009 pdmH1N1 vRNP was substituted with H3N2 PA, a significant increase in activity was observed; whereas when H3N2 vRNP was substituted with 2009 pdmH1N1 PA, a significant decrease in activity occurred. Although, the polymerase basic protein 2 (PB2) of 2009 pdmH1N1 was originated from an avian virus, substitution of this subunit with H3N2 PB2 did not change its polymerase activity in human cells.
\end{abstract}

Conclusions: In conclusion, our data suggest that hybrid VRNPs resulted from reassortment between 2009 pdmH1N1 and H3N2 viruses could still retain a substantial level of polymerase activity. Substituion of the subunit PA confers the most prominent effect on polymerase activity. Further studies to explore the determinants for polymerase activity of influenza viruses in associate with other factors that limit host specificity are warrant.

Keywords: Human swine influenza, Pandemic, Seasonal, PB1, PB2, PA, NP, RNP, RNA polymerase, Pathogenesis

\section{Background}

In April 2009, the Centers for Disease Control and Prevention $(\mathrm{CDC})$ at Atlanta reported that a new influenza virus was found in Mexico and the United States [1]. The new influenza A H1N1 virus was soon characterized $[2,3]$ to be a triple reassortant derived from human, avian and swine influenza viruses [3-5]. The virus spread rapidly worldwide [6] and the World Health Organization (WHO) declared that the pandemic has reached phase 6 on June 112009 [7]. Currently, the virus is still circulating worldwide [7].

\footnotetext{
* Correspondence: paulkschan@cuhk.edu.hk

'Department of Microbiology, The Chinese University of Hong Kong, Shatin, New Territories, Hong Kong Special Administration Region, People's Republic of China

Full list of author information is available at the end of the article
}

Influenza viruses exhibit a restricted host range with limited replication in other species [8-10]. However, on rare occasions, influenza viruses can cross species barrier and adapt to a new host giving rise to a new lineage. Adaptation to a new species is believed to require multiple point mutations or reassortment of gene segments, or both. The molecular mechanism and genetic determinants that restrict, or permit, the replication of influenza viruses in humans remain unclear. While host haemagglutinin receptor specificity is clearly an important factor, it is not an absolute barrier to cross-species infection [11-13]. Growing evidence suggests that viral polymerase and nucleoprotein (NP) play a pivotal role in determining host selection and adaptation $[13,14]$.

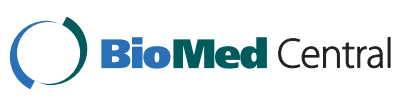

() 2011 Lam et al; licensee BioMed Central Ltd. This is an Open Access article distributed under the terms of the Creative Commons Attribution License (http://creativecommons.org/licenses/by/2.0), which permits unrestricted use, distribution, and reproduction in any medium, provided the original work is properly cited. 
Replication and transcription of influenza RNA segments are regulated by a virus-encoded RNA-dependent RNA polymerase [14]. The polymerase is a heterotrimeric, multifunctional complex composed of three viral proteins, polymerase basic protein 1 (PB1), polymerase basic protein 2 (PB2), polymerase acidic protein (PA), which together with the viral NP form the viral ribonucleoprotein (vRNP) complex that is required for viral mRNA synthesis and replication [14]. PA is an endonuclease [15-19], and involves in promoter and cap binding [20,21]. PB1 contains active sites for nucleotide elongation [22,23] and binding to promoters of vRNA and cRNA [22,24,25]. PB2 involves in cap-snatching from host mRNA [26,27], and has been the focus of host adaptation and pathogenicity study. PB2 mutation, particularly the E627K, has been linked to the adaption of avian viruses to mammalian host [28,29]. Another PB2 mutation, D701N, has been associated with increased virulence in mice [30,31].

Given the current co-circulation of the 2009 pandemic $\mathrm{H} 1 \mathrm{~N} 1$ and seasonal H3N2 viruses, co-infection of these viruses in humans may occur [32]. In this study, the polymerase activity of recombinant vRNP complexes that may be created from the reassortment between these two viruses was examined.

\section{Results}

Polymerase activity of pdmH1N1, H3N2 and WSN H1N1 vRNP complexes

The results of luciferase assays performed with the parental 2009 pdmH1N1, H3N2, and WSN H1N1 vRNPs are shown in Figures 1 and 2. All recombinant vRNPs showed polymerase activity in both A549 and 293T cells under $33^{\circ} \mathrm{C}$ or $37^{\circ} \mathrm{C}$ incubation. A significantly lower level of polymerase activity for the 2009 pdmH1N1 vRNP was observed at $33^{\circ} \mathrm{C}$ compared to $37^{\circ} \mathrm{C}$ for both cells (293T cells RLU ratio: 0.030 vs $0.298, P=0.03$; A549 cells RLU ratio: 0.050 vs $0.371, P=0.01$ ) (Figure 1 ), whereas no significant differences with respect to incubation temperature were observed for WSN and H3N2 vRNPs (Figure 2).

The polymerase activity of 2009 pdmH1N1 vRNP as recorded from $293 \mathrm{~T}$ cells incubated at $37^{\circ} \mathrm{C}$ was significantly lower than that of WSN H1N1 (RLU ratio: 0.498 vs $0.612, P=0.01$ ), and this observation was reproduced in A549 cells (RLU ratio: 0.402 vs $0.533, P=0.01$ ). Furthermore, in A549 cells, the polymerase activity of 2009 pdmH1N1 vRNP was significantly lower than that of $\mathrm{H} 3 \mathrm{~N} 2$ at $33^{\circ} \mathrm{C}$ (RLU ratio: 0.358 vs $0.396, P=0.04$ ) and at $37^{\circ} \mathrm{C}$ (RLU ratio: 0.402 vs $0.479, P=0.01$ ), respectively (Figure 2 ).

\section{Polymerase activity of reassortant vRNPs derived from 2009 pdmH1N1 and H3N2}

Figure 3 shows that the results of luciferase assays obtained from hybrid vRNPs derived from substituting the 2009 pdmH1N1 vRNP with one H3N2 subunit at a time. It was found that substitution with either H3N2 $\mathrm{PB} 1$ or $\mathrm{H} 3 \mathrm{~N} 2 \mathrm{~PB} 2$ resulted in a slightly decrease in polymerase activity, whereas substitution with either H3N2 PA or H3N2 NP resulted in an increase in polymerase activity. The same trend of change in polymerase
A.

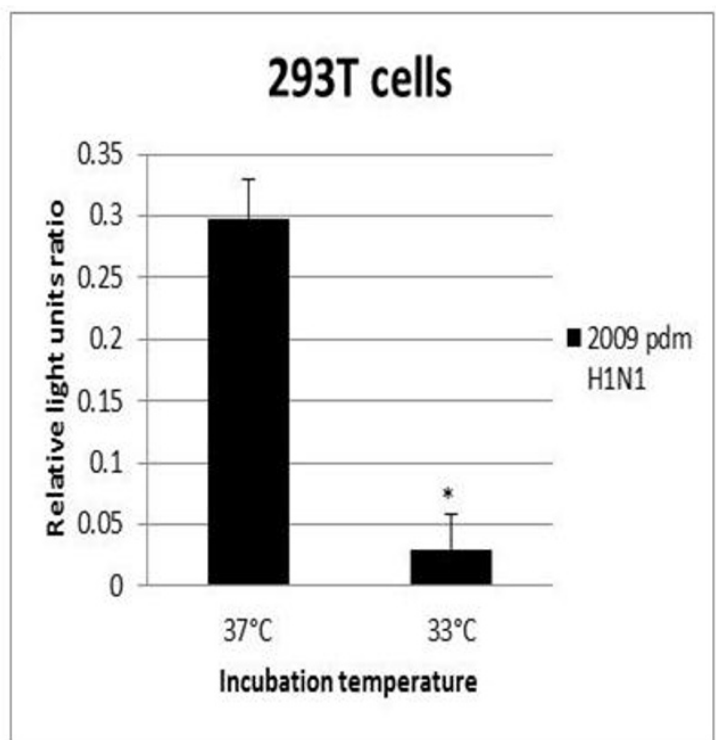

B.

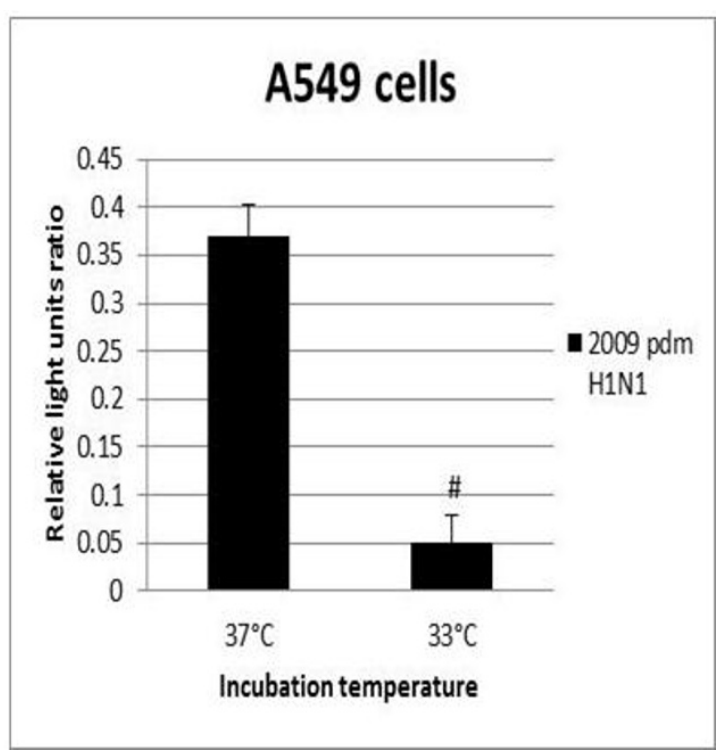

Figure 1 Polyermase activity of vRNP complexes of 2009 pandemic $\mathrm{H} 1 \mathrm{~N} 1$ at $33^{\circ} \mathrm{C}$ and $37^{\circ} \mathrm{C}$. (a) $293 \mathrm{~T}$ cells, $37^{\circ} \mathrm{C}$ and $33^{\circ} \mathrm{C}$. (B) $\mathrm{A} 549$ cells, $37^{\circ} \mathrm{C}$ and $37^{\circ} \mathrm{C}$. Polymerase activity as reflected by the normalized relative light units ratio (mean \pm standard deviation, $\mathrm{n}=3$ ) at $37^{\circ} \mathrm{C}$ compared to $33^{\circ} \mathrm{C},{ }^{*}$ represents statistical significance at $p<0.03$, and \# represents statistical significance at $p<0.01$. 
A.

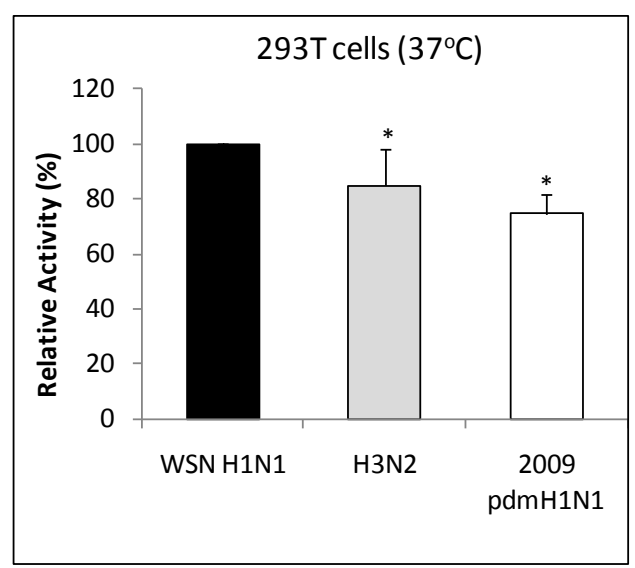

C.

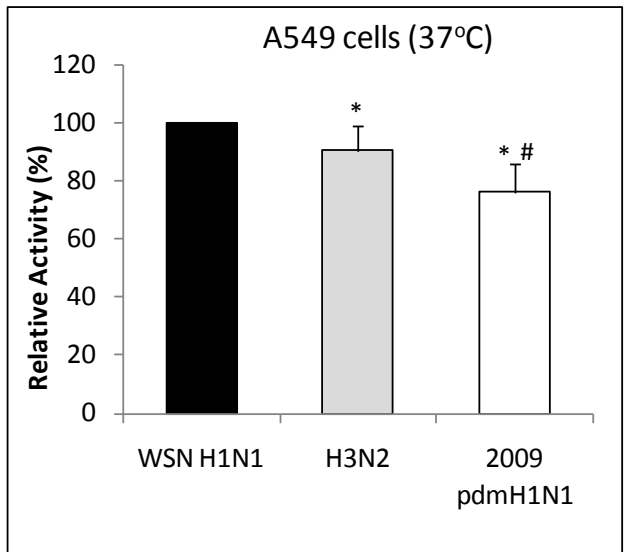

B.

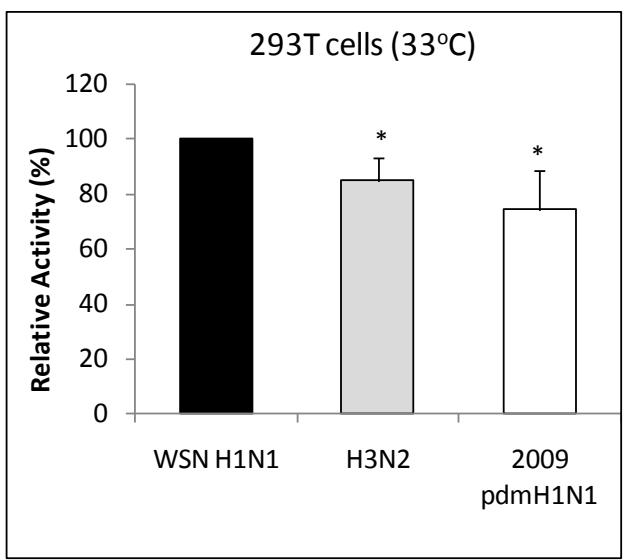

D.

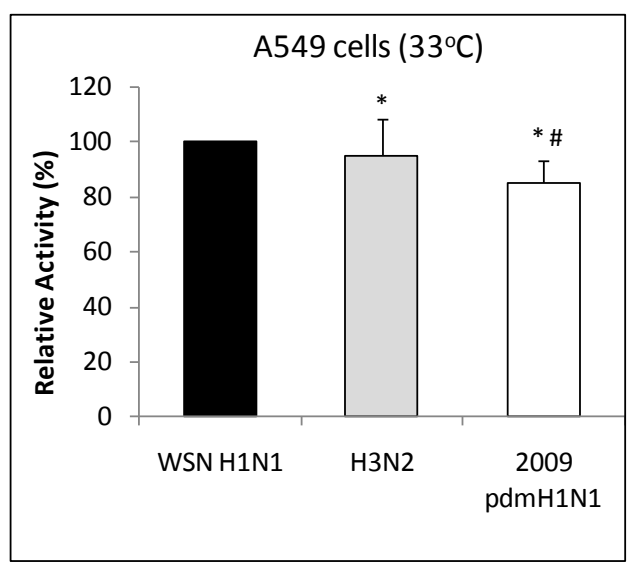

Figure 2 Polyermase activity of vRNP complexes of 2009 pandemic H1N1, seasonal H3N2 and WSN H1N1. (a) $293 T$ cells, 37 $\mathrm{C}$. (b) $293 \mathrm{~T}$ cells, $33^{\circ} \mathrm{C}$. (c) A549 cells, $37^{\circ} \mathrm{C}$. (d) $\mathrm{A} 549$ cells, $33^{\circ} \mathrm{C}$. Polymerase activity as reflected by the normalized relative light units was expressed as relative activity (mean \pm standard deviation, $\mathrm{n}=3$ ) compared to the reference strain WSN H1N1, * represents statistical significance at $p<0.01$ compared to WSN H1N1, and \# represents statistical significance at $p<0.05$ compared to H3N2.

activity was observed in both $293 \mathrm{~T}$ and A549 cells. When subjected to statistical analysis, only the substitution with H3N2 PA showed a significant increase in polymerase activity of the 2009 pdmH1N1 vRNP in 293 T cells (RLU ratio: 0.34 vs $0.43, P=0.03$ ).

The results of reciprocal substitution of H3N2 vRNP with 2009 pdmH1N1 subunit are shown in Figure 4. All hybrid vRNPs with either PB1, PB2, PA or NP derived from 2009 pdmH1N1 showed a decrease in polymerase activity. A statistically significant decrease in polymerase activity was observed for the substitution with 2009 pdmH1N1 PA in 293T cells (RLU ratio: 0.57 vs $0.43, P$ $=0.02$ ).

\section{Discussion}

Viral polymerase has a key function in the virus replication cycle and likely to play a role in host adaptation. Previous studies on polymerase activity of influenza were mainly conducted on $293 \mathrm{~T}$ cells [33]. The results of this study showed that in addition to $293 \mathrm{~T}$ cells,
A549 cells can also serve this purpose. Furthermore, A549 cells could be more appropriate as they are derived from human lung epithelial cells, which is the primary site of replication of influenza viruses.

Our results showed that the polymerase activity of 2009 pdmH1N1 vRNP was significantly lower than WSN H1N1 and H3N2. The difference in activity was more obvious in A549 cells. Although, one could not infer on the transmissibility in humans based on polymerase activity alone, the implication of these in-vitro observations deserves further exploration.

It has been reported that avian influenza viruses are adapted for growth in the avian enteric tract with higher temperature $\left(37^{\circ} \mathrm{C}\right)$, whereas human influenza viruses are adapted for growth at upper respiratory tract with lower temperature $\left(33^{\circ} \mathrm{C}\right)$. It has also been suggested that zoonotic transmission may be limited by temperature differences between the two hosts [3]. In this regard, we compared the polymerase activities of the recombinant vRNPs at $33^{\circ} \mathrm{C}$ and $37^{\circ} \mathrm{C}$. The results 
A.

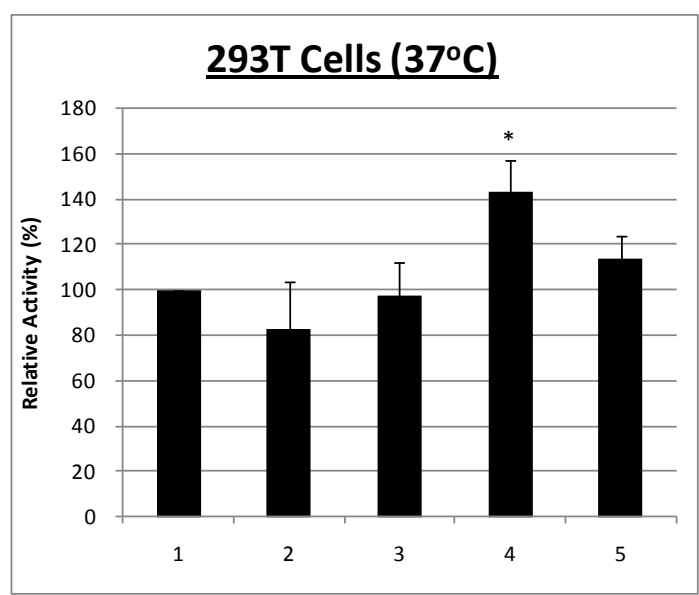

PB1 pdmH1N1 H3 pdmH1N1 pdmH1N1 pdmH1N1

PB2 pdmH1N1 pdmH1N1 H3 pdmH1N1 pdmH1N1

PA pdmH1N1pdmH1N1pdmH1N1 H3 pdmH1N1

NP $\quad$ dmH1N1 pdmH1N1 pdmH1N1 pdmH1N1 H3
B.

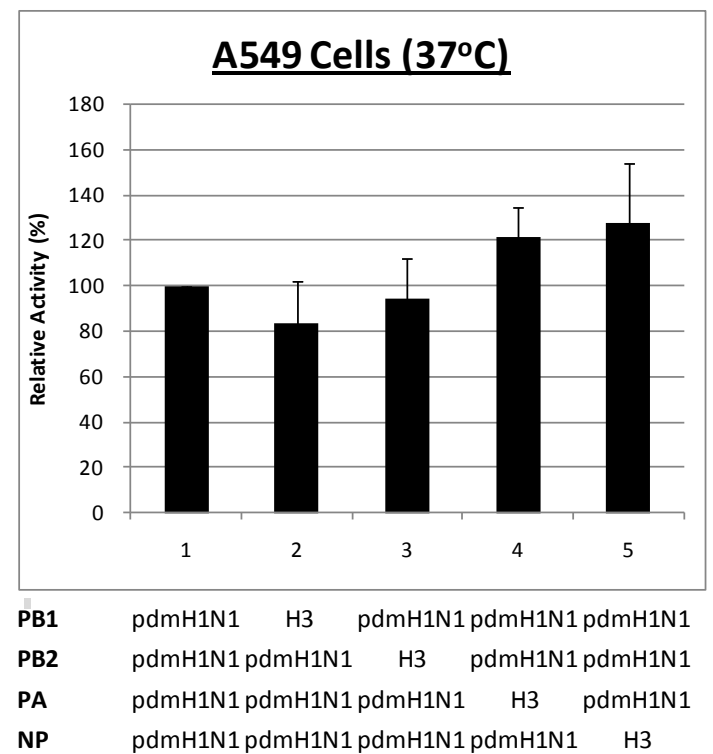

Figure 3 Polymerase activity of 2009 pdmH1N1 vRNP substituted with H3N2 PB1, PB2, PA and NP. Recombinant vRNPs were transfected into (a) $293 \mathrm{~T}$ and (b) A549 cells at an incubation temperature of $37^{\circ} \mathrm{C}$. Polymerase activity as reflected by the normalized relative light units was expressed as relative activity (mean \pm standard deviation, $\mathrm{n}=3$ ) compared to the parent pdmH1N1 vRNP, * represents statistical significance at $p<0.05$.

showed that the 2009 pdmH1N1 vRNP had a significantly lower activity at $33^{\circ} \mathrm{C}$ compared to $37^{\circ} \mathrm{C}$. It would worthwhile to further investigate whether this was attributed to the avian origin of the PB2 and PA segments of 2009 pdmH1N1 virus.
In addition to the avian-origin PB2 and PA, the vRNP of 2009 pdmH1N1 virus is composed of a human-origin PB1 and a classic swine-origin NP. We hypothesized that substitution of one of these vRNP subunits with a human (H3N2)-origin subunit could confer a change in
A.

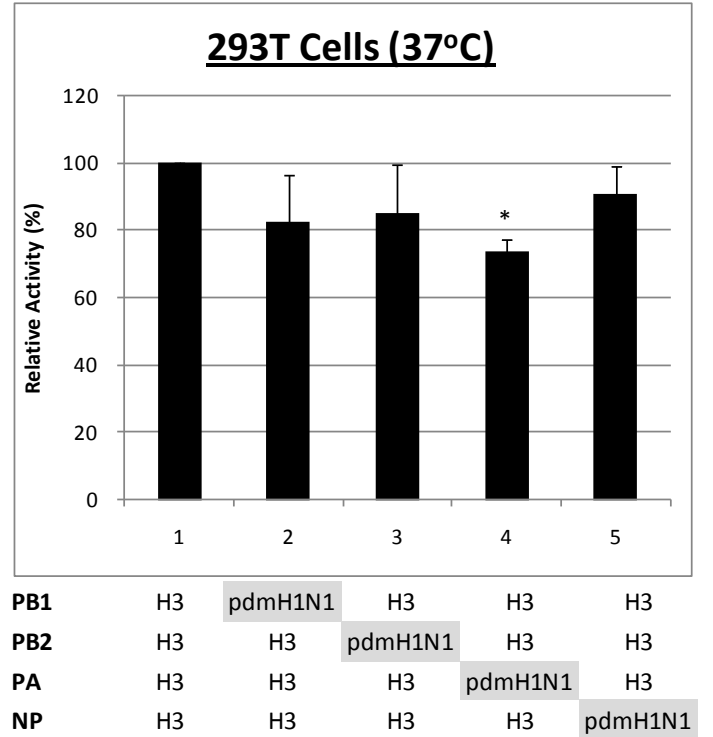

B.

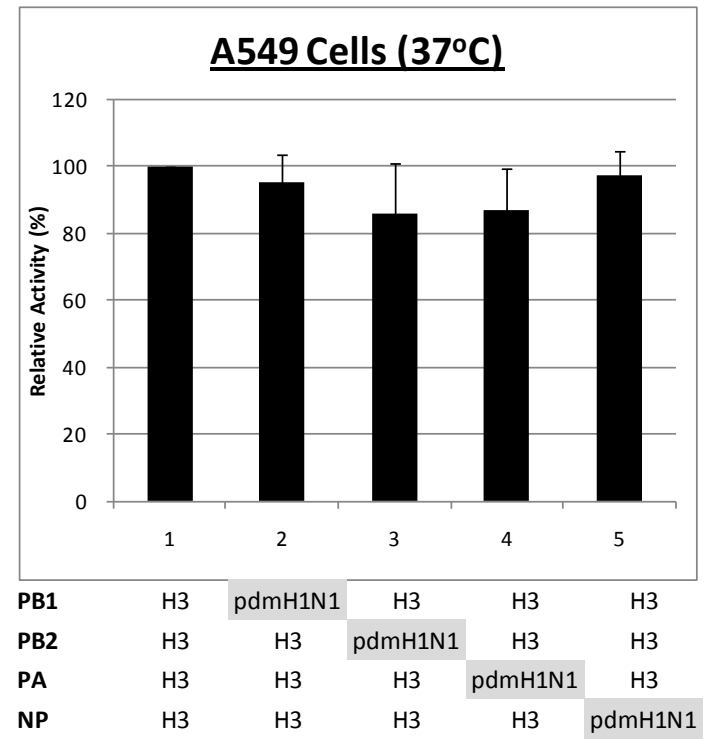

Figure 4 Polymerase activity of H3N2 vRNPs substituted with 2009 pdmH1N1 PB1, PB2, PA and NP. Recombinant VRNPs were transfected into (a) 293T and (b) A549 cells at an incubation temperature of $37^{\circ} \mathrm{C}$. Polymerase activity as reflected by the normalized relative light units was expressed as relative activity (mean \pm standard deviation, $n=3$ ) compared to the parent H3N2 vRNP, * represents statistical significance at $p<0.05$. 
polymerase activity. The results of our vRNP subunit substitution experiment showed that each of the 2009 pdmH1N1 vRNP subunit could be substituted by a corresponding H3N2 subunit, and the hybrid vRNPs still retained a polymerase activity comparable $(\sim+/-20 \%)$ to the parent vRNP. Among these substitutions, an H3N2-origin PA conferred a statistically significant increase in the level of polymerase activity in 293T cells. In reciprocal, a hybrid recombinant H3N2 vRNP substituted with 2009 pdmH1N1 PA subunit showed a significant decrease in polymerase activity in $293 \mathrm{~T}$ cells. The increase in the level of polymerase activity in 293T cells was more significant than that in A549 cells. Since PA forms a dimer with PB1, the increase in activity observed in our study might due to a better compatibility of H3N2 PA with 2009 pdmH1N1 PB1 and vice versa. Our observations are in line with a previous study on $\mathrm{H} 5 \mathrm{~N} 1, \mathrm{H} 1 \mathrm{~N} 1$ and $\mathrm{H} 3 \mathrm{~N} 2$ subtype viruses, where PA was found to be a major determining factor responsible for the enhanced polymerase activity of $\mathrm{H} 5 \mathrm{~N} 1$, while the other subunits had little effect $[34,35]$.

Since the 2009 pdmH1N1 PB2 was originated from an avian subtype lacking the human adaptation mutation E627K [12,36-40], one might expect that the PB2 subunit of H3N2 could increase the polymerase activity of 2009 pdmH1N1 vRNP. As yet, when the 2009 pdmH1N1 vRNP was substituted with a human (H3N2) $\mathrm{PB} 2$, a slightly decrease in polymerase active was observed in both $293 \mathrm{~T}$ and A549 cells. Nevertheless, one should note that the subunits of vRNP are known to interact with each other. For instance, PB2 interacts with PB1 [41-43] and possibly with PA [44]. Substituting the 2009 pdmH1N1 vRNP with a PB2 of H3N2 origin may affect these interactions.

\section{Conclusions}

Overall, our data suggest that hybrid vRNPs resulted from reassortment between 2009 pdmH1N1 and H3N2 viruses could still retain a substantial level of polymerase activity. Substituion of the subunit PA confers the most prominent effect on polymerase activity. Further studies to explore the determinants for polymerase activity of influenza viruses in associate with other factors that limit host specificity are warrant.

\section{Methods}

In-vitro cell models

Two human cell lines of different tissue origin were used as an in-vitro model to examine the polymerase activity of vRNP complexes. The A549 cells were derived from human alveolar basal epithelial adenocarcinoma (ATCC, CCL-185, Rockville, MD, USA), and the 293T cells were derived from human embryonic kidney (ATCC, CRL-11268). These cells were maintained in minimum essential medium (MEM) supplemented with $10 \%$ fetal bovine serum (FBS), $1 \%$ penicillin, and $1 \%$ streptomycin (all from Gibco, Life Technology, Rockville, Md., USA) at $33^{\circ} \mathrm{C}$ or $37^{\circ} \mathrm{C}$ in a $5 \% \mathrm{CO}_{2}$ incubator.

\section{Virus strains}

Three influenza strains were used for preparing cDNA clones correspond to the respective vRNP subunits. The A/Auckland/1/2009 (H1N1) represented the 2009 pandemic H1N1 virus (2009 pdmH1N1), the A/HongKong/ CUHK-22910/2004 (H3N2) represented seasonal H3N2 virus, and the A/WSN/1933 (H1N1) (WSN H1N1) was also included as a reference.

\section{Expression of recombinant vRNPs}

The PB1, PB2, PA and NP-expressing plasmids of WSN H1N1 were kindly provided by Prof. George Brownlee $[20,34]$. The full-length sequences of PB1, PB2, PA and NP of 2009 pdmH1N1 and H3N2 were amplified using Superscript III reverse transcriptase (Invitrogen, Carlsbad, CA) and PCR with Fusion polymerase (Stratagene, La Jolla, CA, USA). PB1, PA and NP PCR products were inserted into pcDNA3A plasmids [33] using KpnI and NotI restriction sites, whereas the HindIII and NotI restriction sites were used for PB2 PCR product. The DNA sequences of the cloned genes were checked by direct sequencing.

The expression plasmids were used to generate recombinant vRNPs as described previously [45]. Briefly, $1 \mu \mathrm{g}$ of each plasmid was transfected into $293 \mathrm{~T}$ or A549 cells by Lipofectamine 2000 (Invitrogen) according to the manufacturer's instructions. The medium of transfected cells was replaced by MEM with 10\% FBS, $1 \%$ penicillin and 1\% streptomycin (all from Gibco, Life Technology) at $6 \mathrm{~h}$ post-transfection.

\section{Luciferase reporter assay for viral polymerase activities}

A series of different combinations of PB2, PB1, PA and NP protein expression plasmids and the pPolI-NP-Luc were co-transfected into $293 \mathrm{~T}$ or A549 cells. In addition, a reporter plasmid pGL4.73[hRluc/SV40], encoding a Renilla luciferase gene, was co-transfected to serve as a control for normalizing the transfection efficiency between experiments. At $48 \mathrm{~h}$ post-transfection, the polymerase activities of recombinant vRNPs were determined. According to the manufacturer's instructions, cells were lysed by using the Steady-Glo assay reagent (Promega, Madison, WI, USA) for $10 \mathrm{~min}$ and the luminescence was measured by a microplate luminometer (Wallac VICTOR3, PerkinElmer, Norwalk, CT).

\section{Data analysis}

All data were generated from three separate experiments. The results of the luciferase reporter assay were 
recorded as relative light units (RLU). The ratio of RLU normalized with the internal control were used for comparing the polymerase activities between different vRNPs. Differences in normalized RLU ratio between two vRNPs were compared by the Student'st-test. Pvalues less than 0.05 were regarded as significant.

\section{Abbreviations}

CDC: Centers for disease control and prevention; CDNA: Complementary deoxyribonucleic acid; cRNA: Complementary ribonucleic acid; D701N: A change of amino acid 701 from aspartic acid to asparagine; E627K: A change of amino acid 627 from glutamic acid to lysine; FBS: Fetal bovine serum; MEM: Minimum essential medium; mRNA: Messenger ribonucleic acid; NP: Nucleoprotein; PA: Polymerase acidic protein; PB1: Polymerase basic protein 1; PB2: Polymerase basic protein 2; RLU: Relative light units; vRNA: Viral ribonucleic acid; VRNP: Viral ribonucleoprotein; WHO: World health organization; 2009 pdmH1N1: 2009 pandemic H1N1 virus; H3N2: A HongKong/CUHK-22910/2004; WSN H1N1: A/WSN/1933 (H1N1).

\section{Acknowledgements}

The H1N1- A/WSN/1933 vRNP expression plasmids were kindly provide by Prof. George Brownlee (Sir William Dunn School of Pathology, University of Oxford). The pandemic H1N1 viral RNA (A/Auckland/1/2009) was kindly provided by lan G Barr, World Health Organization Collaborating Centre for Reference and Research on Influenza, Australia. The study was supported by the Research Fund for the Control of Infectious Diseases, Food and Health Bureau of the Hong Kong Special Administrative Region Government.

\section{Author details}

'Department of Microbiology, The Chinese University of Hong Kong, Shatin, New Territories, Hong Kong Special Administration Region, People's Republic of China. ${ }^{2}$ Stanley Ho Centre for Emerging Infectious Diseases, The Chinese University of Hong Kong, Shatin, New Territories, Hong Kong Special Administration Region, People's Republic of China.

\section{Authors' contributions}

KLKN performed the virus culture, cloning of VRNP plasmids, luciferase reporter assays, recombinant VRNP assays. WYL was responsible for experimental design, analyses and drafting of the manuscript. PKSC was responsible for design and supervision of the study. All authors read and approved the final manuscript.

\section{Competing interests}

The authors declare that they have no competing interests.

Received: 31 August 2011 Accepted: 12 December 2011 Published: 12 December 2011

\section{References}

1. Centers for Disease Control and Prevention (CDC): Update: novel influenza A (H1N1) virus infection-Mexico March-May, 2009. MMWR Morb Mortal Wkly Rep 2009, 58:585-589.

2. Itoh $Y$, Shinya $K$, Kiso M, Watanabe $T$, Sakoda $Y$, Hatta M, Muramoto $Y$, Tamura D, Sakai-Tagawa $Y$, Noda T, et al: In vitro and in vivo characterization of new swine-origin H1N1 influenza viruses. Nature 2009, 460:1021-1025

3. Kashiwagi T, Hara K, Nakazono Y, Hamada N, Watanabe H: Artificial hybrids of influenza A virus RNA polymerase reveal PA subunit modulates its thermal sensitivity. PLoS One 2010, 5:e15140.

4. Dawood FS, Jain S, Finelli L, Shaw MW, Lindstrom S, Garten RJ, Gubareva LV, Xu X, Bridges CB, Uyeki TM: Emergence of a novel swineorigin influenza A (H1N1) virus in humans. N Engl J Med 2009, 360:2605-2615.

5. Peiris JS, Poon LL, Guan Y: Emergence of a novel swine-origin influenza $A$ virus (S-OIV) H1N1 virus in humans. J Clin Virol 2009, 45:169-173.

6. Centers for Disease Control and Prevention (CDC): Update: novel influenza A (H1N1) virus infections-orldwide, May 6, 2009. In MMWR Morb Mortal Wkly Rep. Volume 58. 2009;453-458.
7. World Health Organization (WHO) 2010. Pandemic (H1N1) 2009:[http:// wwwwhoint/csr/disease/swineflu/en/indexhtml].

8. Beare AS, Webster RG: Replication of avian influenza viruses in humans. Arch Virol 1991, 119:37-42.

9. Hatta M, Halfmann P, Wells K, Kawaoka Y: Human influenza a viral genes responsible for the restriction of its replication in duck intestine. Virology 2002, 295:250-255

10. Murphy BR, Sly DL, Tierney EL, Hosier NT, Massicot JG, London WT, Chanock RM, Webster RG, Hinshaw VS: Reassortant virus derived from avian and human influenza $\mathrm{A}$ viruses is attenuated and immunogenic in monkeys. Science 1982, 218:1330-1332.

11. Abdel-Ghafar AN, Chotpitayasunondh T, Gao Z, Hayden FG, Nguyen DH, de Jong MD, Naghdaliyev A, Peiris JS, Shindo N, Soeroso S, et al: Update on avian influenza A (H5N1) virus infection in humans. N Engl J Med 2008, 358:261-273.

12. Hatta M, Gao P, Halfmann P, Kawaoka Y: Molecular basis for high virulence of Hong Kong H5N1 influenza A viruses. Science 2001, 293:1840-1842

13. Leung BW, Chen H, Brownlee GG: Correlation between polymerase activity and pathogenicity in two duck $\mathrm{H} 5 \mathrm{~N} 1$ influenza viruses suggests that the polymerase contributes to pathogenicity. Virology 2010, 401:96-106.

14. Palese P, Shaw ML: Orthomyxoviridae: the viruses and their replication. In Fields Virology.. 5 edition. Edited by: Knipe DM, Howley RM. Philadelphia, PA: Lippincott Williams 1647-1689.

15. Dias A, Bouvier D, Crepin T, McCarthy AA, Hart DJ, Baudin F, Cusack S, Ruigrok RW: The cap-snatching endonuclease of influenza virus polymerase resides in the PA subunit. Nature 2009, 458:914-918.

16. Hara K, Shiota M, Kido H, Ohtsu Y, Kashiwagi T, Iwahashi J, Hamada N, Mizoue K, Tsumura N, Kato H, et al: Influenza virus RNA polymerase PA subunit is a novel serine protease with Ser624 at the active site. Genes Cells 2001, 6:87-97.

17. Hara K, Schmidt Fl, Crow M, Brownlee GG: Amino acid residues in the $\mathrm{N}$ terminal region of the PA subunit of influenza A virus RNA polymerase play a critical role in protein stability, endonuclease activity, cap binding, and virion RNA promoter binding. J Virol 2006, 80:7789-7798.

18. Obayashi E, Yoshida H, Kawai F, Shibayama N, Kawaguchi A, Nagata K, Tame JR, Park SY: The structural basis for an essential subunit interaction in influenza virus RNA polymerase. Nature 2008, 454:1127-1131.

19. Yuan P, Bartlam M, Lou Z, Chen S, Zhou J, He X, Lv Z, Ge R, Li X, Deng T, et al: Crystal structure of an avian influenza polymerase $P A(N)$ reveals an endonuclease active site. Nature 2009, 458:909-913.

20. Fodor E, Crow M, Mingay LJ, Deng T, Sharps J, Fechter P, Brownlee GG: A single amino acid mutation in the PA subunit of the influenza virus RNA polymerase inhibits endonucleolytic cleavage of capped RNAs. J Virol 2002, 76:8989-9001.

21. Maier HJ, Kashiwagi T, Hara K, Brownlee GG: Differential role of the influenza A virus polymerase PA subunit for vRNA and CRNA promoter binding. Virology 2008, 370:194-204.

22. Li ML, Ramirez BC, Krug RM: RNA-dependent activation of primer RNA production by influenza virus polymerase: different regions of the same protein subunit constitute the two required RNA-binding sites. EMBO J 1998, 17:5844-5852.

23. Li ML, Rao P, Krug RM: The active sites of the influenza cap-dependent endonuclease are on different polymerase subunits. EMBO J 2001, 20:2078-2086.

24. Gonzalez S, Ortin J: Distinct regions of influenza virus PB1 polymerase subunit recognize vRNA and CRNA templates. EMBO J 1999, 18:3767-3775.

25. Jung $T E$, Brownlee $G G$ : A new promoter-binding site in the PB1 subunit of the influenza A virus polymerase. J Gen Virol 2006, 87:679-688.

26. Fechter P, Mingay L, Sharps J, Chambers A, Fodor E, Brownlee GG: Two aromatic residues in the PB2 subunit of influenza A RNA polymerase are crucial for cap binding. J Biol Chem 2003, 278:20381-20388.

27. Guilligay D, Tarendeau F, Resa-Infante P, Coloma R, Crepin T, Sehr P, Lewis J, Ruigrok RW, Ortin J, Hart DJ, et al: The structural basis for cap binding by influenza virus polymerase subunit PB2. Nat Struct Mol Biol 2008, 15:500-506.

28. Labadie K, Dos Santos AE, Rameix-Welti MA, van der WS, Naffakh N: Hostrange determinants on the PB2 protein of influenza $A$ viruses control the interaction between the viral polymerase and nucleoprotein in human cells. Virology 2007, 362:271-282. 
29. Subbarao EK, London W, Murphy BR: A single amino acid in the PB2 gene of influenza A virus is a determinant of host range. J Virol 1993, 67:1761-1764.

30. Gabriel G, Dauber B, Wolff T, Planz O, Klenk HD, Stech J: The viral polymerase mediates adaptation of an avian influenza virus to a mammalian host. Proc Natl Acad Sci USA 2005, 102:18590-18595.

31. Li Z, Chen H, Jiao P, Deng G, Tian G, Li Y, Hoffmann E, Webster RG, Matsuoka Y, Yu K: Molecular basis of replication of duck H5N1 influenza viruses in a mammalian mouse model. J Virol 2005, 79:12058-12064.

32. Lee N, Chan PK, Lam WY, Szeto CC, Hui DS: Co-infection with pandemic H1N1 and seasonal H3N2 influenza viruses. Ann Intern Med 2010, 152:618-619.

33. Brownlee GG, Sharps JL: The RNA polymerase of influenza a virus is stabilized by interaction with its viral RNA promoter. J Virol 2002, 76:7103-7113.

34. Kashiwagi T, Leung BW, Deng T, Chen H, Brownlee GG: The N-terminal region of the PA subunit of the RNA polymerase of influenza A/ HongKong/156/97 (H5N1) influences promoter binding. PLoS One 2009, 4:e5473.

35. Song MS, Pascua PN, Lee JH, Baek YH, Park KJ, Kwon HI, Park SJ, Kim CJ, Kim H, Webby RJ, et al: Virulence and Genetic Compatibility of Polymerase Reassortant Viruses Derived from the Pandemic (H1N1) 2009 Influenza Virus and Circulating Influenza A Viruses. J Virol 2011, 85:6275-6286.

36. Le QM, Sakai-Tagawa Y, Ozawa M, Ito M, Kawaoka Y: Selection of H5N1 influenza virus PB2 during replication in humans. J Virol 2009, 83:5278-5281.

37. Manzoor R, Sakoda Y, Nomura N, Tsuda Y, Ozaki H, Okamatsu M, Kida H: PB2 protein of a highly pathogenic avian influenza virus strain A/ chicken/Yamaguchi/7/2004 (H5N1) determines its replication potential in pigs. J Virol 2009, 83:1572-1578.

38. Mase M, Tanimura N, Imada T, Okamatsu M, Tsukamoto K, Yamaguchi S: Recent $\mathrm{H} 5 \mathrm{~N} 1$ avian influenza A virus increases rapidly in virulence to mice after a single passage in mice. J Gen Virol 2006, 87:3655-3659.

39. Steel J, Lowen AC, Mubareka S, Palese P: Transmission of influenza virus in a mammalian host is increased by PB2 amino acids $627 \mathrm{~K}$ or $627 \mathrm{E} / 701$ N. PLoS Pathog 2009, 5:e1000252.

40. Subbarao K, Klimov A, Katz J, Regnery H, Lim W, Hall H, Perdue M, Swayne D, Bender C, Huang J, et al: Characterization of an avian influenza A (H5N1) virus isolated from a child with a fatal respiratory illness. Science 1998, 279:393-396.

41. Gonzalez $\mathrm{S}$, Zurcher T, Ortin J: Identification of two separate domains in the influenza virus PB1 protein involved in the interaction with the PB2 and PA subunits: a model for the viral RNA polymerase structure. Nucleic Acids Res 1996, 24:4456-4463.

42. Ohtsu Y, Honda Y, Sakata Y, Kato H, Toyoda T: Fine mapping of the subunit binding sites of influenza virus RNA polymerase. Microbiol Immunol 2002, 46:167-175.

43. Sugiyama K, Obayashi E, Kawaguchi A, Suzuki Y, Tame JR, Nagata K, Park SY: Structural insight into the essential PB1-PB2 subunit contact of the influenza virus RNA polymerase. EMBO J 2009, 28:1803-1811.

44. Hemerka JN, Wang D, Weng Y, Lu W, Kaushik RS, Jin J, Harmon AF, Li F: Detection and characterization of influenza A virus PA-PB2 interaction through a bimolecular fluorescence complementation assay. J Virol 2009, 83:3944-3955.

45. Fodor E, Devenish L, Engelhardt OG, Palese P, Brownlee GG, Garcia-Sastre A: Rescue of influenza A virus from recombinant DNA. J Virol 1999, 73:9679-9682.

doi:10.1186/1743-422X-8-528

Cite this article as: Lam et al:: Polymerase activity of hybrid

ribonucleoprotein complexes generated from reassortment between 2009 pandemic H1N1 and seasonal H3N2 influenza A viruses. Virology Journal 2011 8:528.

\section{Submit your next manuscript to BioMed Central and take full advantage of:}

- Convenient online submission

- Thorough peer review

- No space constraints or color figure charges

- Immediate publication on acceptance

- Inclusion in PubMed, CAS, Scopus and Google Scholar

- Research which is freely available for redistribution

Submit your manuscript at www.biomedcentral.com/submit
C Biomed Central 